\title{
Azúcar y Modernidad: La experimentación tecnológica de la oligarquía habanera: 1700-1820*
}

\author{
por \\ Mercedes García Rodríguez \\ Universidad de La Habana
}

El artículo aborda la mentalidad de modernización y experimentación tecnológica que acompañó a la élite ilustrada de la oligarquía azucarera de Cuba entre los siglos XVIII y $X I X$. Se demuestra con datos y documentos el marcado interés de este poderoso grupo habanero por hacer crecer la producción del dulce, lo que los condujo a contratar, con fábricas inglesas, la producción de los molinos con un diseño moderno, y materiales constructivos que los hicieron más duraderos y potentes. Mostraremos la diligencia y persistencia de la élite azucarera para lograr sus objetivos económicos y politicos y cómo a través de su vocero Francisco de Arango y Parreño reclamaron al rey autorización para un periplo por Europa y el Caribe de espionaje tecnológico-industrial que les sirvió para introducir nuevas máquinas y tecnología moderna. En este proceso fue fundamental la inversión del capital acumulado por algunos miembros de la élite v las gestiones realizadas por directivos de la Real Compañia de Comercio de la Habana en Cádiz, Bristol y Londres.

Palabras clave: Azúcar; tecnología azucarera; economía; ingenios; oligarquía habanera; modernización tecnológica; siglos XVIII-XIX.

Desde los comienzos azucareros de Cuba, el grupo más poderoso y de avanzada de los criollos propietarios de ingenios tuvo sentido de modernidad en cuanto a la experimentación innovadora en sus unidades, con el claro objetivo de mejorar el tosco y pesado instrumental empleado en los diferentes pasos de la manufactura del dulce, los llamados cobres menudos; pero sobre todo su interés fue fortalecer y revolucionar la rudimentaria y única máquina de sus ingenios: el trapiche o molino, moler más caña en un trapiche más

* Esta investigación se enmarca en el proyecto «Los latidos del progreso en Cuba y Puerto Rico, 1780-1940» (HAR2009-09844) financiado por MICINN. 
potente y duradero, racionalizando recursos y disminuyendo costes, era su anhelo y su necesidad.

Por supuesto, este grupo de hacendados de primera línea de pensamiento y sustanciosos recursos financieros no constituía la mayoría de los productores de entonces. No obstante, sus ensayos e inversiones dieron un impulso importante a la economía de la región occidental, donde se concentraron, y en particular fueron los hacedores del avance azucarero del periodo.

Los oligarcas del azúcar no sólo se interesaron por mejorar el molino, sustituyendo antiguas piezas de madera por otras más duraderas y fuertes construidas de hierro o cobre, sino que al producirse la revolución industrial comenzaron a preocuparse y ocuparse de introducir, de manera rápida y experimental, los últimos avances tecnológicos y agronómicos en sus unidades productivas, especialmente abonos y nuevas especies de caña; también buscaron una mayor racionalización en la organización y división del trabajo, y la aplicación de la botánica y la química en la elaboración de azucares ${ }^{1}$.

Para la década de 1790 aparecieron en La Habana las primeras publicaciones técnicas ${ }^{2}$ que despertaron mucho interés en los propietarios de ingenios. Estos impulsarían a otros hacendados menores a interesarse en aquellos avances científico-técnicos y en la aplicación, en sus unidades productoras, de las nuevas tecnologías, imprescindibles para dar el salto cualitativo y cuantitativo en la producción del dulce. Así la marcada y beneficiosa insistencia de la ilustrada oligarquía habanera en la divulgación y puesta en práctica de los avances alcanzados a nivel mundial desembocó en la creación de la Primera Escuela de Química y Botánica en Cuba, regentada por la Real Sociedad Patriótica Amigos del País.

La historiografía tradicional ha acuñado como verdad, que los trapiches verticales de tres mazas, se construían todos de madera dura hasta finales del siglo XVIII. Moreno Fraginals en su clásica obra El Ingenio, afirma que la primera mención conocida sobre la aplicación de dados y trompos de hierro a un trapiche o molino, en Cuba, corresponde a 1766, y que fueron experimentados en el ingenio «Nuestra Señora de Regla» alias «El Retiro» ${ }^{3}$. Sin

\footnotetext{
1 Para ampliar información puede verse: Moreno Fraginals, 1978, T1; García Rodríguez, 2007.

2 Estas primeras publicaciones eran de origen francés, de la década de 1760, las mismas habían sido traducidas y publicadas en España en los años 80, pero desconocidas en Cuba hasta que algunos ejemplares fueron publicados entre 1792 y 1796, lamentablemente en la actualidad estas obras a penas se encuentran en bibliotecas. Moreno Fraginals, 1978, T.1: 76, ver notas: $51,52,54$ y 55 .

3 Moreno Fraginals, 1978, T.1: 82.
} 
embargo, investigaciones recientes muestran que desde 1701, hubo algunos hacendados que comenzaron a sustituir varias piezas de madera de sus primitivos trapiches, por otras similares de cobre o hierro fundido, lo cual les dio a aquellos molinos mayor fortaleza y durabilidad, reflejándose esta información en varias tasaciones de ingenios que han quedado como testimonio de aquel interés y primeros pasos hacia la modernidad. Por tanto puede afirmarse que ya para mediados del siglo XVIII varios molinos habaneros llegaron a convertirse totalmente en trapiches de tres mazas verticales de hierro, cambios cualitativos que se produjeron mucho antes de la fecha señalada por la historiografía tradicional ${ }^{4}$.

Entre los nuevos hallazgos que permiten realizar esta afirmación está el caso del ingenio San Antonio de Padua, fundado en 1702 por el Capitán Tomas de Urabarro, al oeste del puerto habanero; este tenía montado en su casa de molienda un trapiche de tres mazas, con sus guijos, chumaceras, trompos y dados, todo de metal, con un valor de 600 pesos fuertes, cifra poco común para la época, donde por lo general un trapiche vertical, nuevo y de madera dura costaba entre 300 y 400 pesos. Además, algo que llama la atención, es que este ingenio tenía en su casa de calderas, 3 pailas grandes de cobre, «traídas del Norte», es decir adquiridas en alguna de las antiguas trece colonias inglesas, no se especifica cuál, 2 tachos, y una resfriadera de cobre también traída «del Norte en $1706 »^{5}$. El ingenio en cuestión fue tasado en 1708 , en unos 26.887 pesos de a 8 reales, una verdadera fortuna para la época. Ahora bien, ¿sería el molino del San Antonio de Padua el primer y único trapiche de La Habana con piezas de hierro y cobre en aquellos años?

No existen evidencias suficientes para afirmar que el uso del trapiche de hierro fuera la tendencia en los ingenios de la primera mitad del siglo XVIII, pero al menos los escasos y dispersos datos indican que entre 1702 y 1750 , otros hacendados de la zona ya los poseían. Esta novedad en el campo constructivo del trapiche se explica por los contactos de dichos propietarios con los comerciantes ingleses radicados en las trece colonias y en Jamaica, lugares desde donde se transferían a la isla no sólo tecnología de contrabando por la compañía inglesa de los Mares del Sur poseedora del Asiento de negros desde 1713, sino que a través de estos contactos se introdujeron nuevas modas y tejidos más finos y apropiados al clima insular, que los que mercadeaba España en sus colonias. También por esta vía se obtuvo literatura de avanzada y se introdujeron en Cuba nuevas ideas y formas de construir ingenios con

\footnotetext{
4 Ampliar información en García Rodríguez, 2007.

5 Archivo Nacional de Cuba, La Habana (a partir de ahora: ANC), Fondo: Protocolos de La Habana, Escribanía: Fornaris. Folios 699v-701v.
} 
materiales más duraderos como la mampostería para las paredes y las tejas para los techos 6 .

Sin lugar a dudas las colonias inglesas y el Brasil portugués fueron fuentes de inspiración para buscar, con la experimentación como método, molinos mucho más fuertes, con piezas de recambio hechas de metal fundido, además de comprarse o copiar modelos nuevos, para luego reproducirlos en la isla.

La necesidad de mejorar el proceso productivo despertó la inventiva criolla y se modificó favorablemente parte del instrumental para la casa de calderas y purga hechos de cobre o hierro, como las repartideras de azúcar y los bombones o bombos, etc., cuestión que queda al descubierto en varias tasaciones para ventas de ingenios revisadas para el periodo. Algunos de los más poderosos hacendados compraban este instrumental en las trece colonias, y también negros de contrabando para fuerza de trabajo de los ingenios, pagándolos con hoja de tabaco y azucares, lo que hace suponer que este comercio de intercambio violó el estanco del tabaco, impuesto a la producción y exportación de la hoja, desde 17177 .

Ya para 1750, la Real Compañía de Comercio de La Habana comenzó a transportar hacia Cuba nueva tecnología adquirida en las fábricas inglesas de Bristol, a solicitud de los hacendados azucareros y por encargo particular de algunos ricos propietarios habaneros. Entre los elementos y piezas más demandados estuvieron: trapiches, piezas de hierro de recambio, enormes planchas de hierro y cobre para la fundición de calderas y tachos, e instrumental de cobre, entre otros.

El nuevo rol de La Habanera, no eliminó del todo el contrabando de tecnología y piezas que regularmente, al parecer, se mantuvo por las costas occidentales y centrales de la isla, pues en los frecuentes navíos ingleses apresados se describen con frecuencia máquinas y piezas para ingenios ${ }^{8}$. La Real Compañía encargaba a casas comerciales de Cádiz los modelos de trapiche y las piezas de recambio que estas a su vez solicitaban a las fábricas inglesas y que pagaban a crédito en base a sus producciones de azúcar.

Así, por ejemplo, en 1755, don Ambrosio de Justis encargó a la Real Compañía 6 guijos y 18 trompos de hierro, que condujo a La Habana el navío La Asunción. De su adquisición Justis quedó debiendo a sus proveedores 125

6 García Rodríguez, 2006.

7 García Rodríguez, 2004.

8 Archivo General de Indias (a partir de ahora: AGI), Sección: Escribanía de Cámara. Legajo 101 A y otros variados de ese mismo fondo. 
pesos fuertes, que pagaría con azúcar de calidad superior de su próxima zafra. Ese mismo año la Compañía entregó a don Joseph Antonio Núñez de Villavicencio, en La Habana, su encargo de 4 cajones de guijos de hierro, con peso de 30 quintales, por valor de 210 pesos fuertes que pagó con azúcar de su última zafra y algún tabaco en polvo?.

Por su parte, don Francisco de la Guardia, de visita en Cádiz, en 1764, embarcó con permiso de la Compañía, 30 piezas de hierro para su ingenio fundado en Managua, cuyo peso era de 27 quintales $^{10}$. Al año siguiente, todavía en Cádiz, de La Guardia pide un nuevo permiso a La Compañía para remitir a La Habana, en uno de sus buques, 4 guijos, 4 trompos y 2 dados, todo de hierro fundido, fabricados en Vizcaya, por encargo de un habanero propietario de ingenio, sin identificar, que le pagaría con azúcar a su llegada; estas piezas tenían un peso de 12 quintales y 65 libras, y un valor de 157 pesos fuertes ${ }^{11}$. Estos ejemplos, evidencian que Cuba y su manufactura del dulce no iban a la zaga del resto de las islas azucareras del Caribe, como ha repetido gran parte de la historiografía tradicional, sino a la par, y en algunos momentos de fines de siglo podría decirse que en la avanzada. No obstante, no debe perderse de vista que los nuevos avances de la revolución industrial se introdujeron más lentamente en el renglón azucarero a escala internacional, que en otros sectores productivos como la industria textil o la minería.

A mediados del siglo XVIII comenzaron a construirse en los ingenios habaneros las hornillas o fornallas en forma de túnel corredizo, alimentado por una sola boca de fuego, esta estructura permitía aprovechar mucho mejor el calor, que lo logrado con el tradicional tren español de hornillas de fuegos individuales. Con este túnel corredizo de fuego se logró disminuír apreciablemente el consumo de leña, cuestión que empezaba a tornarse una preocupación para los propietarios de ingenios con escasas tierras boscosas en sus unidades azucareras.

Moreno explica que: «cuando un grupo de pailas se colocaba sobre un mismo cañón de fuego se le llamaba tren o sistema de hornos de reverbero, [y que] los primeros trenes de este tipo introducidos en Cuba, fueron los (mal) llamados franceses, constituidos por cinco pailas en sucesión de mayor a menor $(\ldots)\rangle^{12}$.

\footnotetext{
9 AGI, Ultramar, legajo 259.

10 Idem.

11 Idem.

12 Moreno Fraginals, 1978, T.I: 214.
} 
Hasta hoy no se ha podido precisar con exactitud la llegada a la isla de este nuevo sistema de reverbero o cañón de fuego único, que alimentaba a varias hornillas, denominado tren francés, al que también se le conoce como tren jamaiquino o tren de reverbero. Moreno asegura que ya en 1780, algunos ingenios habaneros habían construido y utilizaban con éxito el llamado tren francés ${ }^{13}$. Sin embargo, la información descriptiva de algunos inventarios y tasaciones de haciendas azucareras anteriores a esa fecha, evidencian que este sistema de un solo fuego ya se usaba en La Habana posiblemente desde la década de 1750, con la denominación de tren de reverberos, como se llamaba en las colonias inglesas de Jamaica y Barbados, donde se empleaba desde la década de 1720. Evidentemente los criollos copiaron este sistema de Jamaica y lo conocieron por sus relaciones de comercio ilegal ${ }^{14}$.

Sobre la discutida paternidad de este sistema de tren de reverbero o cañón de un solo fuego, Moreno y también Noel Deer han afirmado que, con el paso del tiempo, los propios técnicos azucareros franceses reconocieron que el tren, al que ellos habían denominado francés, era una copia casi exacta del sistema inglés de pailas y túnel de un solo fuego, y que, con algunas ligeras modificaciones, lo habían comenzado a emplear en sus colonias, entre 1725 y $1730^{15}$, mientras que los ingleses lo empleaban en sus colonias azucareras desde los primeros años del setecientos.

Ciertas evidencias en diferentes tasaciones de ingenios conducen a afirmar que para 1750 ya se empleaba, al menos, el principio del cañón de un solo fuego en varios de los ingenios occidentales de Cuba, Así, por ejemplo:

En 1759, fue tasado el ingenio Nuestra señora de Guadalupe y San Francisco de Paula, este poseía en su Casa de Calderas un fogón con sus hornillas o fornallas para 3 pailas y 2 tachos $^{16}$, se precisa que aquel fogón alimentaba, al parecer a modo de cañón de fuego, las 5 bocas de fuego, entonces denominadas fornallas.

Después de la expulsión de la Compañía de Jesús, en 1767, sus ingenios fueron dados a administrar a la Junta de Temporalidades, y esta los confió a mayorales, a administradores de ingenios y al administrador General de la Junta. En las cartas cruzadas del Administrador General de la Junta y el Administrador del ingenio Barrutia, entre 1767 y 1768., hay algunas que la llaman la atención sobre sus capacidades productivas interiores, exponemos dos de ellas a continuación:

\footnotetext{
13 Ibidem: 215.

14 García Rodríguez, 2007.

15 Moreno Fraginals, 1978. T-1: 215-216. Deer, 1942.

16 ANC, Escribanía Junco, año: 1759, folios 400-407v.
} 
Del Administrador del ingenio Barrutia, al Administrador General de Temporalidades:

(...) cuando usted guste puede mandar un maestro albañil que entienda poner las pailas de reverbero, al estilo moderno y reparar las antiguas fornallas $(. . .)^{17}$. [Este trabajo de montaje y reparación, se concluyó en diciembre de 1767].

Del Administrador General, Antonio P. Echarum a Antonio Sánchez, administrador del Barrutia:

(...) tengo entendido que el negro que cuida de cebar el fuego de las pailas de reverbero, es el mismo que debe atenderlas y limpiarlas, y en efecto, es así como se practica en todos los ingenios de leña, pero como este es de brusca y bagazo, apenas se pone al reverbero se acaba y por consiguiente baja el hervor de las pailas, que no pueden limpiarse como se debe por estar el negro ocupado en echar más bagazo y brusca al fuego; por lo que ha de prevenir al mayoral de ese ingenio que destine un negro únicamente para cebar el fuego, que no se mueva del reverbero, y otro negro se destine como pailero para atender las calderas, sobre todo para espumar y limpiar esas pailas $(. . .)^{18}$.

Estas muestran que ya desde la década de 1760, o incluso antes, se empleaba en algunos ingenios habaneros, no sólo este llamado tren de reverberos o cañón de un solo fuego en serie, sino también permiten reconocer cierto interés de la oligarquía por la racionalización de recursos forestales, cuando temen que las grandes zafras están dando muerte al bosque y deciden emplear la brusca y el bagazo en sustitución de la leña con vistas a alargar la vida útil de sus haciendas azucareras ${ }^{19}$.

En referencia a la composición interna del ingenio, como unidad productora, el concepto económico que primó durante los siglos XVII y XVIII, fue el del sistemático crecimiento cuantitativo de las fuerzas productivas internas en cada unidad, y no exactamente la del desarrollo de las mismas. Fue este modelo de crecimiento cuantitativo el que marcaría la tendencia de los hacendados azucareros criollos hasta prácticamente el salto del ingenio al central, a fines del siglo XIX.

17 AGI. Sección: Cuba, legajo 1101. Carta del Administrador del ingenio Barrutia, Antonio Sánchez al administrador General de temporalidades. Octubre de 1767.

18 AGI, Sección: Cuba. Legajo 1101. Carta del Administrador General de Temporalidades al Administrador del ingenio Barrutia. 2 de enero de 1768. La utilización de la cursiva y el subrayado son de la autora. Al respecto y para profundizar en el funcionamiento y prácticas productivas de los ingenios Jesuitas en Cuba ver: García Rodríguez, 2000.

19 Para un mayor conocimiento de la incidencia negativa de las plantaciones azucareras sobre los bosques y medio ambiente en general ver: Funes, 2008. 
El modelo de crecimiento cuantitativo cubano, y caribeño en general, es de una simplicidad pragmática muy evidente, en buena medida determinada por el atraso y empirismo que caracterizó a la manufactura azucarera hasta fines del siglo XVIII. A los señores del azúcar de Cuba no les quedó otra alternativa que sumar más trapiches a su tren productivo para ampliar las capacidades de molienda, pero con ello debieron hacer crecer, en forma equivalente, el número de calderas y tachos y por ende el tren o los trenes de fuego en sus casas de calderas. Por supuesto, aumentarían necesariamente el número de hormas para la purga y así sucesivamente tendrían que aumentar todos los eslabones de la cadena productiva, especialmente la fuerza de trabajo, para poder dar respuesta a la cadena de producción en serie, que caracterizó la elaboración del dulce ${ }^{20}$.

Pero para que este crecimiento cuantitativo en la manufactura del dulce resultara eficiente, debía existir a priori, la suficiente cantidad de tierras destinadas a producir caña y los brazos necesarios para cortarla; por ello tierras y fuerza de trabajo esclavo fueron una preocupación permanente de los hacendados del setecientos.

El caso del ingenio San Francisco de Paula, alias, Gavilán, construido en 1769 por Bartolomé de los Reyes Gavilán, en tierras de Managua, nos permite ejemplificar la tendencia al crecimiento cuantitativo del renglón azucarero. En la tasación que se realizó a dicho ingenio en 1782, se describe en detalles que en su casa de molienda y calderas poseía ya tres trapiches, dos más del que poseía en 1760 cuando se fundó por su propietario y dos trenes compuestos cada uno por 3 pailas grandes y 2 tachos, cuando en 1760 se había inaugurado con 4 simples fornallas individuales y sus correspondientes calderas. Además se tasa gran cantidad de hormas para la purga, aunque no se especifican cuantas, y se advierte la existencia de un tren desbaratado por su largo uso, del cual recomendaba el tasador, «debían sacarse sus piezas y fundirse, y con el producto de su venta y la solicitud de un pequeño préstamo invertir en un nuevo trapiche» ${ }^{21}$.

Aunque la tasación es de 1782, la evidencia de un tren de fuego en serie, ya roto por su uso frecuente, nos reafirma en la idea que el sistema de reverbero al estilo inglés ya se empleaba en Cuba mucho antes de los años 80 , aunque este tren no representó por si solo una revolución tecnológica.

20 García Rodríguez, 2007. Funes, 2008.

21 ANC, Fondo: Escribanía de Varios. Legajo 502, Núm. 7514. Expediente que contiene el Testimonio de los autos del entestado Bartolomé de los Reyes Gavilán, que trata sobre el traspaso a su esposa del ingenio Gavilán. 
Moreno en su constante repensar sobre la manufactura, aseguraba en uno de sus escritos posteriores a El Ingenio, que aún mediante el uso de una moderna batería de calderas sobre un tren jamaicano, la evaporación al aire libre suponía un desperdicio muy importante de los niveles de rendimiento en el proceso de concentración ${ }^{22}$. Por tanto, el uso del tren de reverberos, no fue factor determinante en el crecimiento de los volúmenes productivos, pero si un agente multiplicador de las capacidades energéticas, en la medida que dicho sistema racionalizó la utilización de los recursos maderables.

Entre 1775 y 1780 fue construido el ingenio San Rafael, cuyas características corresponden a las de un ingenio de los denominados modernos o nuevos, pues tenían signos que sellaban su construcción de avanzada, por ejemplo, en su estructura y terrenos poseía una casa de molienda de mampostería con dos trapiches todos de metal y otro en piezas, por montar. En su casa de calderas tenía construido un tren de reverbero, con 4 cobres sentados y sus tinglados; además poseía otros 2 fogones con 5 bocas de fuego y una casa grande de bagazo; su dotación, de 48 esclavos, era mixta, 22 negras y 24 negros, casi todos casados 23 ; esta unidad estaba situada en tierras de Bajurayaguas y era propiedad de Ambrosio Sayas Bazan. Dicho ingenio y el mencionado anteriormente confirman que mucho antes de 1780 ya se empleaban en La Habana los trenes de reverberos, al estilo de los de Jamaica, de ahí el nombre de tren jamaicano, y confirman también que el ingenio de la segunda mitad del setecientos es una unidad mayor por adición de tierras, trapiches y otros componentes, no porque se produjera en ellos aun una revolución tecnológica ${ }^{24}$.

En la década de 1780, conocidos ya en Cuba los progresos de la revolución industrial inglesa, se incentiva el interés de los hacendados azucareros más ilustrados por sumar a sus unidades productivas aquellos avances de los que se hacía eco la prensa de diferentes países. Hasta ese momento la construcción de ingenios y molinos se conceptuaba como un simple trabajo de carpintería y herrería inteligente e ingeniosa ${ }^{25}$, de ahí el nombre de ingenios con el que se nombró a estas iniciales manufacturas del dulce.

Con el avance del setecientos el pensamiento de los productores criollos varió. Estos hacendados, inicialmente empíricos y sin un concepto claro y

22 Moreno Fraginals, coletivo de Autores, 1997: 206-221.

23 ANC, Bienes de Estado, legajo 10, Núm. de orden 9. Expediente de Diligencias seguidas por el subteniente Ambrosio Vicente de Sayas Bazan para enajenar su ingenio San Rafael, hipotecado a las Temporalidades.

24 García Rodríguez, 2007.

25 AGI, Fondo: Ultramar, legajo 120, doc. 9. Memoria de M. Lafaye sobre los molinos de La Habana y sus trabajos para mejorarlos. 
capitalista de sus empresas azucareras; produjeron sin evaluar la contabilidad y racionalidad de sus unidades, pero con el devenir de la ilustración y tras la revolución industrial y las ventajas del comercio libre de 1778; estos dieron un salto a la modernidad que se advierte en la transformación de su pensamiento económico y de sus formas administrativas. Este salto cualitativo de la segunda mitad del siglo XVIII se expresa en las preocupaciones de esta elite productora por reducir gastos productivos y aumentar la fabricación del dulce y su calidad con vistas al mercado, pero sobre todo en aplicar los controles de gastos y haberes en sus ingenios, esto también les permitió avanzar en la racionalización pretendida.

Será en el último trimestre del setecientos que se evidencie, a nivel de la sociedad insular, estos primeros atisbos de mentalidad empresarial en algunos hacendados azucareros ilustrados de La Habana; que dicho sea de paso y contradictoriamente se radicaron en la ciudad, donde construyeron sus residencias, y en su mayoría llevaban una vida licenciosa, especialmente esto se advierte en su descendencia criolla.

Los hijos de estas familias principales de propietarios azucareros tuvieron en su gran mayoría una tendencia al derroche, al lujo, a la vida en grandes palacetes, y entregados al ocio y al juego, que los hizo perder en unos años las fortunas que sus padres y abuelos habían amasado en años. También sus afanes aristocráticos los llevó a solicitar títulos de nobleza y limpiezas de sangre, acciones que llevaron a este grupo oligárquico a invertir miles de pesos en la compra de favores y privilegios que otorgaba la corona. Ello supuso la no inversión, o más bien el desvío de estos recursos financieros acumulados, que en vez de ir hacia la necesaria reposición y ampliación de las capacidades productivas, se malgastó en comprar títulos y en apuestas de juego y otros vicios y placeres.

Sin dudas, la falta de austeridad y racionalidad en los gastos de una gran parte de los señores de ingenios, que vivían como verdaderos señores feudales-esclavistas, se contradice con su espíritu experimental y emprendedor, dicotomía que condujo a la gran mayoría de esta oligarquía del azúcar a la banca rota, a mediados del siglo XIX, debido a que no tuvieron capacidad de respuesta para sus montañas de deudas ${ }^{26}$.

No obstante a lo dicho, desde mediados del setecientos un grupo de ricos dueños de ingenios, quizás minoritario aún, estuvieron interesados en buscar nuevos métodos productivos para sus campos y una nueva fuente de energía para sus manufacturas de azúcar, dada la probada viabilidad económica del

26 Para comprender mejor este modo de vida y de prácticas financieras de la oligarquía azucarera de La Habana ver: García Rodríguez, 2004. 
renglón por los excelentes precios del dulce. Especialmente los azucareros más ricos e ilustrados del periodo se propusieron alcanzar la construcción de un molino más adecuado a la robustez de las cañas de Cuba, que ejercían una fuerte resistencia y presión en el proceso de su molienda, tratando de solucionar con ello las roturas continúas de los endebles molinos de bueyes. Resolver esta necesidad productiva los llevó a incentivar y financiar proyectos experimentales para alcanzar un trapiche mucho más eficiente y resistente. En tal sentido hicieron esfuerzos para traer a la isla a técnicos e ingenieros de avanzada, con el fin de introducir en sus ingenios cambios revolucionarios desde el punto de vista productivo.

Entre los más destacados técnicos e ingenieros llegados a Cuba en ese periodo con intereses en experimentaciones tecnológicas es importante destacar al técnico francés Esteban M. Lafaye, que a instancias de varios hacendados ilustrados, y muy ricos, estableció un taller de máquinas en La Habana. Lafaye, aupado y financiado por esta oligarquía habanera e incluso por el propio Capitán General don Luis de Las Casas, comenzaría a poner una atención especialísima en el funcionamiento de los molinos de azúcar movidos por bueyes, los más abundantes por entonces en Cuba, para descubrir sus defectos y proyectar molinos de mayor eficiencia en la molienda en términos de rendimientos y aprovechamiento del guarapo extraído; trabajó también por racionalizar los animales de tiro que se requerían para cada zafra.

En general, la oligarquía azucarera de La Habana, siempre bien informada pese a las dificultades de comunicación en la época, conocía de los trabajos que en tal sentido había realizado y continuaba ejecutando el ingeniero $\mathrm{Mr}$. Veret, considerado entonces el artista de molinos de azúcar más importante e instruido de Santo Domingo. Sin embargo, Veret fue criticado tanto por Lafaye como por Arango, pues ambos coincidieron en afirmar que sus malos cálculos sobre la fuerza que ejercían las cañas al entrar al trapiche fueron los responsables directos de que sus diversos modelos de molinos fracasaran, aunque le reconocieron las modificaciones importantes y efectivas que realizó al viejo trapiche de bueyes, de las cuales probablemente partió Lafaye ${ }^{27}$.

27 Según ambos críticos, el señor Veret, calculó que por la resistencia de la caña, los animales que mueven el trapiche tenían que vencer en cada momento un peso equivalente a $30 @$, y dar sin embargo tres vueltas en un minuto, que siendo aproximadamente una circunferencia de 70 varas, resultaría un espacio de 210 varas... y advertían, si esta fuera en realidad la resistencia de la caña en el trapiche las vueltas en un minuto tendrían que ser más y también mayor el número de los animales que debían hacer girar el molino. Ver: AGI. Fondo: Ultramar, legajo 120, doc. 9. Memoria de M. Lafaye sobre los molinos de La Habana y sus trabajos para mejorarlos. 
De sus estudios del molino de bueyes, Lafaye descubrió, desde su estancia en Santo Domingo ${ }^{28}$, que sus dientes se estaban haciendo con defectos muy negativos para el proceso de molienda, pues muchos no tenían las proporciones que requerían los diámetros de las mazas o cilindros de aquellas máquinas, y fue consciente de ello a la hora de concebir su nuevo modelo de trapiche, al cual aplicó los principios de la mecánica y la relojería que advierten que todos los componentes de un mecanismo deben ser bien proporcionados, por ello decía a sus mecenas de La Habana: «(...) los dientes y mazas de un molino, que son partes esenciales de este (...) deben estar siempre en correcta armonía y correspondencia para alcanzar un funcionamiento armónico y eficiente (...) por ello es principalísimo lograr vencer con la técnica esta dura resistencia de la caña a su entrada al molino, si esta se reduce, se reducirá también el número de animales asociados al trapiche y las roturas por no comunicación correcta entre dientes y mazas, por ello pondré todos mis conocimientos de mecánica en función de resolver este problema (...)» ${ }^{29}$.

En su taller habanero Lafaye construyó, a expensas de varios propietarios de ingenios ilustrados, un trapiche novedoso de tres masas de hierro horizontales, pero a diferencia de los anteriores empleados en la isla, estas mazas estaban colocadas a distintos niveles, sobre un triangulo escaleno, ocupando cada eje un vértice del triangulo. El movimiento de este molino era producido por el vaivén de un enorme péndulo, el que se impulsaba por vez primera y después cada cierto tiempo, por uno, dos o más negros, según su tamaño, esto lo convertía en un molino de fuerza motriz humana, reduciendo el empleo de una gran cantidad de animales de tiro, a primera vista el trapiche pendular parecía exitoso por los ahorros que suponía, pero al final resultó un fracaso.

28 Lafaye vivió en Santo Domingo durante varios años en las décadas de 1770-80, isla azucarera en la que experimentó bastante para mejora el molino de sangre, después de años de observación del tradicional molino de bueyes en aquella isla, construyó un nuevo modelo de molino de azúcar, que fue revisado por los comisarios de una Asamblea Colonial constituida y nombrada al objeto de examinarlo, aprobándolo por considerar su futura gran utilidad, pero según lo que nos deja conocer Lafaye en su Memoria de Molinos: «...las rebeliones de negros y las constantes malogradas zafras por condiciones ajenas a la máquina inventada por mí, me hicieron abandonar Santo Domingo y dirigirme a Cuba donde me han dado sus propietarios una gran acogida (...). Y todos me han animado desde mi llegada a emplear mis conocimientos de mecánica y física en buscar soluciones a los molinos de la isla experimentando en sus ingenios, además de garantizarme los recursos financieros necesarios para mi vida y trabajo...». AGI. Fondo: Ultramar, legajo 120, doc. 9. Memoria de M. Lafaye sobre los molinos de La Habana y sus trabajos para mejorarlos.

29 AGI, Fondo: Ultramar, legajo 120, doc. 9. Memoria de M. Lafaye sobre los molinos de La Habana y sus trabajos para mejorarlos. 
Sobre su nueva máquina de moler nos dejó una semblanza el propio Lafaye:

(....) Mi máquina es mucho más ágil que los molinos que tienen montados [los hacendados habaneros]... para colocar mi nuevo molino solo se necesitaría un espacio de 8 a 10 varas de cuadro, un solo negro debe imprimir con facilidad y sin fatiga el movimiento de un péndulo, el que por medio de un móvil intermedio comunica el movimiento de rotación a un volante horizontal, y este a todo el resto de la máquina. Este negro puede relevarse cada media hora, o cada hora, por otro que será remplazado por el primero y así sucesivamente, de suerte que con dos o tres negros que roten entre ellos se soluciona la molienda del día.

En este nuevo molino un solo negro se ocupa de pasar la caña entre las masas, pues la pone sobre una tabla horizontal en frente de la unión de cilindros del medio con el inferior, que también están en posición horizontal; la máquina misma, sin otra ayuda, obliga la caña a pasar otra vez por el primero y la maza superior, sin que por esto se extravié a derecha o izquierda, con el empleo de unos aros de hierro que encajonan las cabezas de los tres cilindros, y los contiene, de forma que sale la caña perfectamente exprimida, entera y ya convertida en bagazo para ser un excelente combustible en las calderas [aunque no se precisa el nombre de este artefacto pudiera ser la llamada Volvedora o Volvedera que aparece en la documentación escrita en ambas formas, y Lafaye, nos sigue contando:], tampoco se necesita negro alguno para extraer este bagazo final del molino, cuando sale, el propio mecanismo de molienda lo tira a fuera y un negro sin mucho esfuerzo puede recogerlo y apilarlo, para luego secarlo un poco y llevarlo a la casa de calderas (....) [Otra ventaja de este nuevo molino, continua informando, es que:] las carretas pueden descargar la caña frente o al lado mismo del molino, porque este ocupa un espacio pequeño y resulta ser plano, con lo cual se ahorran, de la casa de molienda, los negros llamados juntadores o burreros, que en los molinos antiguos realizaban la operación de tirar la caña y meterla al trapiche, trabajo muy peligroso, pues dichos negros debían esperar entre vuelta y vuelta de las mulas, para en ese intervalo correr a meter las cañas entre los rodillos, por ello hay muchos accidentes, no así en este molino de mi invención $(. . .)^{30}$.

Calculó que su molino pendular podía resistir unas 10 o 12 zafras, casi el doble de lo que duraba uno tradicional de bueyes. Y advertía: «(...) en mi nuevo molino los dientes no se gastan o rompen, pues he evitado su rozamiento continuo, para ello he colocado pequeños móviles que dividen los dientes y controlan la fuerza que ejercen entre si(...)» $\rangle^{31}$. Según expertos en construcción de máquinas de la época, el mayor logro de Lafaye consistió en la exactitud y escrupulosidad con que estuvieron diseñadas y colocadas cada una de sus piezas en el molino, todas ellas encajaban a la perfección, como un reloj de precisión, esto fue la base de su triunfo a largo plazo, pues con
30 Idem.
31 Idem. 
este engranaje perfecto evitó las frecuentes roturas del molino tradicional motivadas al gastarse con mucha frecuencia las partes de la máquina que mayor presión recibían, al no estar sus piezas montadas en perfecto equilibrio, presentando desajustes.

En realidad, su innovación de aplicar tres mazas de hierro a un molino horizontal, colocadas sobre un triangulo escaleno, permitió construir en años posteriores un molino de mayor calidad, resistencia y productividad, superando ampliamente al molino tradicional de bueyes, que giraba sobre un mismo eje. Esta solución de tres mazas horizontales, echó los cimientos para el futuro salto al molino de vapor.

En estas tres últimas décadas del setecientos, junto de la experimentación tecnológica y al ensanchamiento de las capacidades productivas instaladas en las unidades azucareras; los oligarcas del azúcar inician un movimiento para solicitar reformas económicas imprescindibles con vías a alcanzar el crecimiento del renglón; específicamente en enero de 1792, Francisco de Arango y Parreño, adalid del grupo azucarero occidental, apelando a sus excelentes relaciones con prohombres de la corte española escribe su ya clásico y conocido Discurso sobre la Agricultura de La Habana y medios de fomentarla, en buena medida para justificar esas necesidades de reformas y apoyar las intenciones de los más ricos barones del azúcar que, atraídos por los adelantos de la revolución industrial, proyectaban iniciar un periplo por diferentes potencias y colonias para aprender y decidir sobre cómo incorporar a sus empresas las nuevas tecnologías y también dónde adquirirlas.

Resulta curioso que muchos de los miembros de la corte, algunos muy cercanos a la oligarquía habanera como el Primer Conde de Pozos Dulces, el Marqués de Herrera y el Marqués de Bejamar, se opusieran a un documento anexo, firmado por Arango, y entregado junto al Discurso sobre la Agricultura..., por el cual este solicitaba permiso al Rey para el mencionado periplo criollo de observación y aprendizaje por el Caribe inglés y francés y por algunas potencias europeas. También criticaron el discurso como algo ofensivo al desempeño metropolitano en sus colonias. ¿Complejos de colonizadores ineptos o acción en defensa de intereses que iban por un camino contrario a la Plantación?, quizás hubo un poco de ambas cosas. Y esto se observa en los argumentos que les hicieron llegar a Gardoqui y al rey:

[...] el viaje que solicita Arango no lo encontramos necesario, ni conducente para mejorar, ni adelantar ninguno de los frutos de la Habana, e Isla de Cuba, ni para la adquisición y gobierno de negros, ni para la formación de aranceles [...] además de inútil, ese viaje resulta inconducente [...] su Discurso y su petición son también injuriosos y ofensivos a todos los españoles, que después de haber conquistado las indias, y sido los primeros Agricultores de todas las especies particu- 
lares del nuevo y antiguo mundo, españoles que llevaron allá la caña que trajeron a esta Península y a las Canarias desde el Asia, e introdujeron los negros para proporcionar mejor las labores [...] se les califica por parte de Arango como inhábiles y aun cuando los extranjeros elogian nuestras producciones, don Francisco de Arango y Parreño quiere ir a buscar instrucciones a fuera para hacer mejoras en La Habana, habiendo dentro de la casa maestros y modelos muy buenos y que puede consultar y adquirir más fácilmente y a menor costo [...].

La Isla logra abundantes y excelentes cosechas de caña y produce también un azúcar de primerísima calidad que nada tiene que envidiar a las que se producen en otras colonias extranjeras [...] para que se requiere entonces mayor conocimiento sobre este renglón $[\ldots]^{32}$.

Estos negativos e intrigantes argumentos cortesanos contra el proyecto de la oligarquía habanera, representado y defendido por Arango, no alcanzaron el éxito y una vez más el proyecto plantacionista habanero logró, apoyándose en una red de relaciones y parentescos, alcanzar sus propósitos. Entre estas figuras cercanas al Rey que defendieron la propuesta de Arango, estuvo Diego Gardoqui, quien estaba tratando de impulsar una política de ilustración para que las colonias pudieran servir con sus producciones y esplendor comercial al reino, logrando con ello mayores ganancias fiscales para la corona y la hacienda real.

Gardoqui desempeñó un papel de suma importancia para España y en particular colaboró con la prosperidad azucarera de Cuba. Él fue también quien puso en contacto a Arango y al Conde de Casa Montalvo con el mejor ingeniero español en máquinas don Agustín de Betancourt, quien residía por ese entonces en Inglaterra. Betancourt trabajaba precisamente en Inglaterra para apropiarse de los conocimientos más modernos en las tecnologías a las que se aplicaba el vapor con vistas a preparar a ingenieros españoles en la nueva tecnología 33 .

Gardoquí, a quien el rey había pedido opiniones sobre el discurso y solicitud de viaje de Arango, expresó por escrito a S.M. que todo lo expuesto por Arango le parecía inteligente y necesario para el fomento de una isla que potencialmente podría convertirse, de realizarse algunas reformas y apoyar algunos de sus proyectos, en la mayor proveedora de recursos y dinero a las arcas reales, en sus palabras, que exponemos sintéticamente se expresan con mayor claridad estos criterios:

He revisado con particular atención el discurso y proyecto que presenta Francisco de Arango sobre la agricultura en La Habana (...) el discurso prueba que

32 AGI, Fondo: Ultramar, legajo 120, doc. 9. Carta del Consejo a Diego de Gardoqui y al Rey. Octubre de 1792.

33 Egórova, 2010: 48-54. 
aquella isla está aún atrasada y que todos sus ramos necesitan de mayor fomento y extensión, y propone: un viaje de instrucción por Europa y América: el establecimiento de una Junta de agricultura en La Habana y ciertas gracias de la corona que favorezcan su desarrollo, por lo que a continuación expondré mi dictamen sobre tales asuntos:

El viaje será muy útil, porque hay en efecto mucho que aprender en esta materia, y me parece a propósito debe hacerlo el mismo Arango, acompañado por el Conde de Casa Montalvo, este último (...) ayudará después a implementar todo tipo de progreso en la isla. Arango debe ir como autor del proyecto y porque él se interesará más que ningún otro por la gloria de su eficaz ejecución.

La Junta que propone y para lo que se intenta será también muy útil y más a propósito que un Consulado como aquí pretenden algunos (...).

Así, si se estableciera un Consulado en La Habana, como se ha solicitado por algunos, conviene que se reduzca al conocimiento de los pleitos mercantiles, o lo más a los puntos que deban ver con el comercio, dejando los asuntos de agricultura sólo para la Junta en el estilo que Arango propone (...).

Sobre las gracias que solicita Arango a la Corona dejo expresadas mis puntos de vista:

1. Se permitirá a los extranjeros que introduzcan negros, pero no podrán dejar apoderados en la isla.

2. Conviene conceder la rebaja de 4 reales por arroba a la exportación de azucares pues ello fomentaría su extracción.

3. No veo la utilidad a España de la gracia que se pide para el azúcar, de que se le permita venir al reino ya refinada, en realidad este rubro de la refinación debe desarrollarse en la metrópoli más bien que en sus colonias.

4. No podemos conceder la extracción del dinero de Veracruz y México para La Habana libre de derechos, de todas formas habrá que analizar los antecedentes de porque se prohibió y ver los inconvenientes que liberarlo pueda acarrear a la corona.

Estos son Señor [refiriéndose al rey] mis conclusiones y dictamen sobre el proyecto de Arango que me pasó ud. para su análisis y respuesta, la última recomendación es que V.M. atienda con gran interés al gobierno de Cuba pues nada hay más importante que atender a extender el cultivo y facilitar el beneficio de sus frutos, proporcionándoles al mismo tiempo salidas ventajosas, y en Cuba, que es la isla más floreciente de las de S.M., el cultivo, el beneficio y las salidas son todavía muy inferiores a sus proporciones naturales, que bien aprovechadas bien bastarían para enriquecer al estado (....) teniendo en cuenta que sus solicitantes son de nuestros más fecundos hijos en ultramar, propongo a Ud. favorecerlas (... $)^{34}$.

Este inteligente análisis de Gardoqui, ganó los favores del rey para el proyecto habanero y se aprobó el viaje de exploración tecnológica y algunas reformas del sistema tributario y administrativo de la colonia. Sin embargo, se le impuso a Cuba el Real Consulado de Comercio y Agricultura contrario a la

34 AGI, Fondo: Ultramar, legajo 120, doc. 9. Carta de Diego de Gardoqui al Rey. 11 de octubre de 1792 . 
Junta de Agricultura proyectada desde el Discurso de Arango, es evidente que el rey quiso compensar de algún modo al grupo cortesano opuesto a Arango.

En 1793, Francisco de Arango y Parreño, en compañía de Ignacio Montalvo y Ambulodi Primer Conde de Casa Montalvo, parten de Madrid e inician el periplo que habían proyectado por Portugal e Inglaterra y las colonias de esta última: Barbados y Jamaica, que concluye en 1795; algunos autores aseguran que también visitaron Haití. Este largo viaje que, como el mismo Arango confirmaba, lo realizaron «empleando otros nombres y como de contrabando ${ }^{35}$, condición necesaria para poder acceder a los conocimientos e información tecnológica que ellos necesitaban, resultó muy provechoso a la oligarquía habanera del azúcar.

La visita de Arango a Inglaterra supuso la apertura a la entrada de tecnología de punta en Cuba, para la pujante industria del azúcar que ya se perfilaba exitosa. De nada valió el celo inglés en referencia a sus nuevos descubrimientos, con el objetivo de mantener la exclusividad de su tecnología y lograr mayores ganancias, tampoco importaron mucho las regulaciones para las salidas migratorias de técnicos e ingenieros durante estos años, y la protección monopólica que mantuvieron en referencia a la máquina de vapor, el dinero criollo todo lo venció y se encargaron dos proyectos de máquinas de vapor, para disgusto de algunos hacendados azucareros ingleses.

Los años finales del setecientos fueron para Cuba años dorados en los que se pudo aprovechar gradualmente los nuevos avances de la tecnología, a la par que sacar buen partido a las condiciones geoestratégicas de su entorno, como por ejemplo el espacio dejado por Haití en el mercado internacional después de su revolución y las coyunturas de guerras europeas que provocaron el alza en la demanda y los precios del dulce.

Es importante apuntar que se lograron aprovechar las coyunturas pues la isla estaba preparada desde mucho antes para el despegue azucarero y por ello Cuba se convirtió en pocos años en la gran azucarera del mundo ${ }^{36}$.

Existen evidencias documentales que muestran el amplio uso de este molino de Lafaye en La Habana a fines del setecientos. Una de estas pruebas es el enorme volumen de piezas de repuesto y nuevos encargos de trapiches de tres mazas horizontales que hacen los hacendados occidentales entre $1790 \mathrm{y}$ 1800 al Administrador de la Real Compañía de Comercio de La Habana don Juan Francisco de Oliden y Arriola, quien, debido a la cantidad de pedidos, encargaba la compra de piezas de repuesto, de hierro y cobre, para los trapiches

\footnotetext{
35 Cornide, 2005: 190.

36 Para ampliar sobre los orígenes azucareros de Cuba se recomienda García Rodríguez, 2007.
} 
habaneros de esta tipología a las Casas comerciales Monsagrati, hijos Montis y Cia, de origen italiano, radicada en Cádiz, y a la Casa Vial e hijo, de Santander, las cuales comercializaban en el puerto de Cádiz el azúcar procedente de Cuba; a la vez que usaban sus relaciones comerciales con el puerto inglés de Bristol para tramitar las solicitudes de piezas de repuesto y de la nueva tecnología para los hacendados criollos, encargos que se realizaban a partir de los modelos de molinos elegidos por los azucareros desde La Habana.

En mayo de 1795, por ejemplo, Francisco de Oliden y Arriola remitió a la Casa Comercial Vial e hijo un pedido de 50 juegos de trapiches «modernos», es decir de tres mazas de hierro horizontales montadas sobre un triángulo escaleno, y varias piezas sueltas de recambio para los del envío anterior, entre ellas 60 guijos de hierro, 100 dientes de cobre y 6 mazas para tambor, para ello envió a la compañía de Santander, varios cajones conteniendo los modelos de molinos que los hacendados de La Habana solicitaban. En julio de ese año, el representante de la Casa Vial e hijo responde a Arriola:

(...) Se están haciendo por nuestra parte todas las diligencias y aplicaremos toda nuestra atención para ejecutar los pedidos (...). Los productores y comerciantes ingleses de las Indias Occidentales encargan los dientes para sus trapiches del mismo metal que hacen las mazas de los tambores [de hierro fundido] pues les cuestan poco en comparación a los gastos de los de cobre que usan en La Habana; se lo insinuamos a Ud. para que lo explique a sus amigos [habaneros] (...). Si se decidieran a experimentar mandaríamos en próximos envíos algunos dientes de hierro (...).

En Bristol necesitan se les haga un crédito a través de Londres de 8 a 10 mil libras esterlinas como adelanto para la compra de los materiales con vistas a la fabricación de los juegos de trapiche solicitados. Según cálculos precisos de los fabricantes ingleses, un juego de trapiche está valorado hoy en unas 169,7 libras esterlinas $(\ldots)^{37}$.

Los elementos y datos aportados nos permiten concluir que la tecnología del molino en los ingenios habaneros del setecientos estuvo a la par de la empleada en las colonias azucareras americanas, tanto inglesas, como de otras potencias. No es por tanto muy realista la afirmación de la historiografía tradicional que considera a la Cuba del setecientos como una colonia atrasada y con gran desfase productivo y tecnológico respecto a las Sugar Island del Caribe, idea que transmitió Arango en su discurso como estrategia para reclamar atención y reformas de España. Tampoco es atinado hablar de Medioevo cubano en los siglos XVII y XVIII, como si el país estuviera congelado en ese tiempo histórico. Todo lo contrario, en estos siglos, Cuba estuvo experimentando opciones económicas y apostó finalmente al azúcar dependiendo

37 AGI. Sección: Ultramar, legajo 806. 
solo de su interés y capitales, todo ello pese a la miopía política española y su terco monopolio comercial que asfixiaba el progreso insular. No es descabellado entonces afirmar que la búsqueda de la modernidad caracterizó siempre a los habitantes de Cuba, a la que no por gusto muchos llamaban: «La isla de los ensayos»».

Y si de ensayos se trata hay pruebas suficientes en las tasaciones de ingenios protocolizadas en La Habana entre 1700 y 1800, de que a lo largo de esos cien años se experimentó primero con el molino de agua, al estilo del de Brasil y Jamaica. Pero este no fue muy práctico para Cuba y sólo se aplicó allí donde los recursos medio ambientales de la región lo permitieran, por ejemplo en los ingenios: La Ninfa, Nueva Holanda y Amistad levantados en las fértiles tierras de Güines. En ellos, sus propietarios supieron aprovechar muy bien las ventajas de las aguas del río Mayabeque, también en las primeras décadas del setecientos en algunos trapiches de agua montados en las márgenes de la chorrera, del río Almendarez ${ }^{38}$.

Pero por la escasez de ríos caudalosos en el occidente de la isla, la tendencia fue la utilización del trapiche de hierro de tres mazas movido por bueyes, que hizo muy rentable la manufactura en zonas más áridas ya que los gastos de su construcción, montaje y mantenimiento resultaba mucho menor que los que hubiera generado la instalación de molinos hidráulicos alejados de los ríos y debiendo construir grandes embalses. Los hacendados consideraron entonces que su mejor solución eran los molinos tirados por bueyes, su construcción resultaba relativamente barata, y su fuerza de tracción: mulos y bueyes, era abundante y fácil de criar y reproducir en los potreros, con excelente pasto, cercanos a los ingenios o establecidos en algún terreno del fundo destinado a la manufactura.

Sin dudas la selección de los tipos de molino a emplear, de acuerdo a las características de cada unidad, fue una excelente estrategia de los hacendados criollos del setecientos, quienes al parecer seguían una máxima: «¡lo mejor y más avanzado no resulta siempre lo más útil!», pensamiento que nos advierte de un pragmatismo muy arraigado en el hacendado criollo que debió dispersar riesgos y evitar inversiones muy costosas en sus empresas agrarias teniendo en cuenta los ciclones, y los periodos de secas o por el contrario de copiosos temporales habituales en el verano caribeño.

En el plano de las mentalidades y estrategias productivas, los años finales del setecientos marcaron una nueva, prometedora y ya necesaria renovación tecnológica para la fabricación del dulce a escala mundial, y Cuba no se que-

38 García Rodríguez, 2007. 
daría atrás ${ }^{39}$. Esta revolución tecnológica a nivel mundial en el azúcar sería iniciada con la invención de las llamadas «volvedoras», con las «clarificadoras», con los sistemas de estufas para el secado rápido de las hormas de azúcar, entre otras importantes innovaciones, que llegan a su clímax al intentar la aplicación del vapor al molino azucarero, en forma experimental por los años de 1770, aunque estos intentos fracasaran en sus inicios, fue el primer gran paso de un largo camino hacia la industrialización azucarera. En realidad, no fue hasta la primera mitad del siglo XIX, con la aplicación del sistema de centrifugado al vacío, junto al vapor aplicado al molino, que se logró la combinación tecnológica perfecta para el desarrollo acelerado del renglón azucarero, tanto a nivel mundial, como en Cuba.

Por supuesto, el alto costo de estas nuevas tecnologías nacidas de la revolución industrial, condicionó que solo un reducido número de propietarios, todos muy ricos e ilustrados, pudieran acceder al progreso. Este quedaba muy distante, y como en un sueño, para aquellos productores medianos y pequeños, generalmente empíricos en sus métodos organizativos y prácticas productivas. Esta diversidad en los productores-propietarios explica la heterogeneidad de la industria azucarera que pasa e incluso trasciende el siglo XIX.

Ello explica que solamente en los ingenios habaneros, propiedad de azucareros ilustrados y muy ricos, comenzaran a insertarse los últimos avances representados, como ya apuntamos, por las volvedoras, las estufas para el secado en la casa de purga, las clarificadoras y la máquina de vapor, esta última, introducida de forma pionera en Cuba por las gestiones del ideólogo de los azucareros don Francisco de Arango y Parreño y el importante hacendado ilustrado Ignacio de Montalvo Ambulodi Conde de Casa Montalvo; la misma fue costeada por Joaquín de Santa Cruz y Cárdenas Conde de Mopox y Jaruco, emparentado con las figuras antes mencionadas y uno de los más ricos hacendados y comerciantes de la ciudad, además de ilustrado caballero que llegó a ocupar cargos relevantes en la Corte española y a proponer y desarrollar la importante Expedición de Guantánamo.

La experimentación con el vapor en el renglón azucarero, como se sabe, tuvo resultados positivos en la larga data, pero en el proceso de encontrar la vía más efectiva fueron apareciendo soluciones parciales al problema principal. Entre 1780 y 1800 a los nuevos molinos de tres masas se sumaron otros elementos tecnológicos de progreso como las clarificadoras montadas en la casa de calderas de los ingenios La Alejandría, del Conde Alejandro de O'Relly, y La Ninfa, de don Francisco de Arango y Parreño. Ambos construidos entre 1792 y 1798.

39 Para recrear esta época puede verse González-Ripoll, 1999. 
Los estudiosos de la tecnología azucarera han calificado como de muy provechoso la utilización de estas clarificadoras, aun cuando por falta de especialistas que se encargaran de su atención y su elevado costo, su empleo fue bastante limitado en la isla hasta los primeros años del siglo XIX en que su aplicación se fue generalizando. Moreno afirma que la introducción y uso de las clarificadoras y otros inventos tecnológicos «fue un notable avance técnico dentro de la rudimentaria fabricación de azúcar de la época» ${ }^{40}$ y un símbolo del cambio de proa a la modernización del renglón.

La máquina de vapor, introducida en Cuba de forma experimental en 1797, se instaló por vez primera en el ingenio Seybabo, propiedad de Joaquín de Santa Cruz y Cárdenas, Conde de Mopox y Jaruco, esta máquina adquirida en julio de 1796 en Inglaterra se echó a andar el 11 de enero de 1797, pero su empleo no brindó los resultados esperados.

Su triunfo definitivo se produjo después de 1817, cuando se ideó acoplar una bomba de vapor a los trapiches horizontales de tres mazas de hierro, especialmente a los fabricados por la casa Fawcett, con ello se logró eliminar entre 50 y 60 yuntas de bueyes de la casa de molienda y entre 10 y 12 esclavos que las atendían, lo cual indiscutiblemente representó un notable ahorro en inversiones, hombres y animales ${ }^{41}$, y por ende fue un paso de avance en la producción.

Recientemente han aparecido nuevas evidencias sobre el ingeniero que ideó y construyó la primera máquina de vapor para ser llevada a Cuba, por iniciativa de Francisco de Arango y Parreño y el Conde Ignacio Montalvo Ambulodi. Proyecto que financió el Conde de Mompox y Jaruco. Este fue el ingeniero en máquinas de origen Canario, y radicado por entonces en Inglaterra, don Agustín de Betancourt, quien construyó esta primera máquina en la Fábrica Reynolds, en Bristol, Inglaterra, entre 1795 y 1796, por encargo expresó de Francisco de Arango y el Conde de Casa Montalvo ${ }^{42}$. Varios documentos encontrados y contrastados así lo confirman:

En el fondo de Pérez Beato ${ }^{43}$ se conserva copia del original de la carta de Arango a uno de sus amigos en España, Francisco de Equino, en que le trata y da indicaciones acerca de la transportación de la máquina de vapor a Cuba, en ella le advierte:

No hay que decir cosa alguna de la bomba de fuego, ni del modo de hacer su pago pues sobre esto se ha dicho lo suficiente en la notita que he firmado con el

\footnotetext{
40 Moreno Fraginals, 1978, T.1: 215.

41 Idem.

42 Egórova, 2010: 54-57.

43 Biblioteca Nacional de Cuba, Fondo Pérez Beato, documento número 968.
} 
conde de Casa Montalvo y en la obligación que igualmente debo firmar en compañía del mismo próximamente.

Don Agustín de Betancourt, que ha sido el director de estas obras y el que inmediatamente se ha obligado con ellas, queda encargado de recibirlas y reconocerlas luego que estén concluidas: y por lo que toca a su remisión, lo mejor sería que sin tocar en puerto alguno de la América inglesa fuesen a La Habana (...) [y le indica]:

1. No se debe perder tiempo (...) interesa que la máquina llegue a La Habana cuanto antes.

2. (...) dar por bien pagado su transporte desde Bristol a cualquier otro puerto (...) prevengo que se remita a Jamaica desde Bristol por el primer convoy que salga para allí asegurando su importe y avisándome el nombre del buque, el tiempo de su salida y la persona a quien va consignada en Jamaica, para que me sirva de gobierno en los ulteriores pasos.

Es incierto todavía donde deben hacerse los cilindros que han de acompañar esta bomba y aunque a mi por todas razones me parece lo mejor que se hagan en la misma fábrica de Reynolds todo lo dejo a la voluntad del referido D. Agustín de Betancourt, a cuya disposición ya se sabe que han de ponerse las doscientas libras esterlinas que por mi parte he depositado en poder del Sr. Equino, luego que llegue de España la responsabilidad convenida.

Si el Sr. Conde de Jaruco, residente en Madrid, tuviese alguna variación que hacer sobre esos particulares para la mejor dirección de la bomba o trapiche, su voluntad debe ser seguida en todo $(\ldots)^{44}$.

De acuerdo con esta carta, es evidente que Francisco de Arango conoció y negoció el proyecto de la máquina de vapor con el ingeniero Betancourt, en 1794. Betancourt era considerado entonces el ingeniero más destacado de España, ocupó en los años 80 responsabilidades importantes por designación del Ministro Floridablanca, de quien era protegido, además de ser amigo personal del también Ministro Gardoqui. En 1790, fue nombrado director de la Escuela de canales, caminos y puentes de Madrid y para esa fecha era uno de los ingenieros de más prestigio en Europa ${ }^{45}$.

Entre Arango y Betancourt se suscribió en Londres un acuerdo acerca de la fabricación de una máquina de vapor para moler la caña de azúcar en Cuba que sería una especie de experimento para poder medir sus resultados respecto a los trapiches al uso y decidir luego su fabricación en serie si resultaba eficiente. Este plan fue apoyado por los hacendados habaneros de mayores capitales, pues como se conoce, la aplicación inmediata de una novedosa tecnología siempre resulta cara para quien lo intenta y no todos los propietarios de ingenios podrían asumirla de inmediato.

\footnotetext{
44 Idem.

45 Egórova, 2010: 60.
} 
Por su parte, Betancourt, hombre ilustrado y muy informado para su época sabía que además de obtener una importante cifra de dinero por su máquina, si lograba aplicar con éxito el vapor a la producción de azúcar se consagraría en su carrera como constructor de máquinas avanzadas para la industria y ocuparía un lugar cimero en la historia tecnológica de la producción azucarera mundial. Precisamente su presencia en Londres respondía a un interés muy personal, anterior a su contacto con Arango. Betancourt estaba deseoso de conocer de cerca la labor ingeniera de Watts y el funcionamiento de sus máquinas de vapor, lo que explica que se conectara rápidamente con las pretensiones de aplicar la modernidad del vapor a la fabricación del dulce, propuesta sugerida por él a los dos representantes de la sacarocracia criolla habanera, y que ellos aceptaron de inmediato, pues en verdad era lo que iban buscando.

El entusiasmo desbordante del ingeniero por su futura experimentación con el vapor se advierte en una carta íntima que le escribe a su amigo, el famoso constructor y diseñador de relojes, Abraham-Louis Bréguet, en diciembre de 1794:

(..) Este verano estuvieron aquí dos amigos de la América española y les propuse el proyecto de colocar en sus posesiones las bombas de fuego para evitar la utilización de los bueyes y negros que necesitan para moler la caña de azúcar; les hice los cálculos y me hicieron rápidamente el encargo de fabricar dos de estas máquinas diseñadas por mi y que ya están haciéndose. En este trabajo pude informarme de todos los defectos de las máquinas que se usan en las islas inglesas, francesas y españolas y traté de evitarlos. Acabo de inventar una máquina compuesta por varios cilindros que:

1) Usa tres negros menos que la máquina más perfecta que existe.

2) Cuesta menos.

3) No precisa de un manejo especial.

4) Su uso no implica riesgos y evita así las frecuentes desgracias que traen otras máquinas;

5) Con la misma fuerza se hace el doble de trabajo. Dos de estas máquinas serán terminadas en breve y espero que se vea su efectividad en las islas y los dueños desechen las que tienen ahora y me encarguen otras nuevas ${ }^{46}$.

Para 1795 las máquinas encargadas estaban ya a punto de ser terminadas, y de ello da cuenta Arango en reunión de la Junta de Gobierno del Consulado, de 14 de octubre de 1795, presidida por el Excmo. Sr. Gobernador y Capitán General. En ella Arango rindió informe del periplo que realizó por diferentes países y colonias, y comunicó a la Junta el modelo de la máquina de vapor que mandó hacer el Conde de Casa Montalvo en Inglaterra para mover los trapiches y presentó al mismo tiempo un modelo pequeño y varios

\footnotetext{
46 García-Diego, 1985.
} 
planos en que se manifestaba el mecanismo de la nueva máquina, según le había indicado el ingeniero jefe Betancourt ${ }^{47}$.

En la siguiente sesión de la Junta de Gobierno, celebrada el 21 de octubre de 1795, Arango comunicó que con el último correo de España había recibido noticias de que la máquina de vapor cuyo modelo y diseño había presentado en la última sesión ya estaba terminada y que sería enviada a Cádiz y de allí al puerto habanero:

Al respecto Moreno afirma: «Finalmente, en 1796, llega a Cuba la fuerza motriz de la gran industria: el vapor. Es una máquina comprada en Londres con dinero del conde de Jaruco. Su instalación fue un suceso único rodeado de un clima de tensa expectación. Y se le vio funcionar el día 11 de enero de 1797 en el ingenio Seybabo: molió durante varias semanas» ${ }^{48}$. El experimento no alcanzó el éxito esperado, pero los sacarócratas no se desanimaron. Arango, al parecer, preocupado por el inicial fracaso de esta máquina, intentó justificarlo ante el Ministro Gardoqui teniendo en cuenta todo el apoyo que este le había brindado a su proyecto, por ello, para diciembre de 1797 le escribe:

La máquina se colocó en uno de los ingenios del Conde de Jaruco, hoy de Santovenia, en donde existen todavía algunas piezas; marchaba con bastante regularidad el día que dio inicio la molienda, aunque se detenía con frecuencia y hubo que abandonarla por falta de un maquinista inteligente. Esta desgraciada circunstancia nos privó por varios años de los beneficios del descubrimiento más admirable de nuestra época ${ }^{49}$.

El vapor aplicado al molino azucarero no triunfaría en Cuba hasta 1817, pero si de algo sirvió la máquina de vapor de Betancourt fue para incentivar aún más la experimentación y búsqueda del progreso por parte de estos hacendados ilustrados y ricos, que tuvieron la clara percepción de que la tecnificación azucarera era posible y muy necesaria, el progreso entonces, para ellos, solo era cuestión de tiempo.

En el siglo XVIII, tanto en Cuba, como en el resto de las colonias de plantación, la tecnología azucarera se estaba reacomodando a raíz de los avances que se fueron presentando con la revolución industrial, en este reajuste los cambios se manifestaron más hacia el perfeccionamiento del molino y de los instrumentos de trabajo existentes, que en la introducción de cambios e innovaciones tecnológicas que revolucionaran la eficiencia de los trapiches de

\footnotetext{
47 Arango y Parreño, 1952: 257-258.

48 Moreno Fraginals, 1978, T.1: 225.

49 Arango y Parreño, 1952: 258.
} 
cualquier modelo y fuerza motriz. En esencia, la producción continuaba determinada primordialmente por la cantidad de trabajo humano empleado en cada jornada laboral. Por ello, la organización del trabajo, el aprovechamiento óptimo de la tierra cultivable y el empleo adecuado del tiempo de labor fueron cuestiones claves y determinantes en la productividad lograda por cada unidad azucarera del setecientos.

\section{Fuentes CONSUltadAs}

Archivo General de Indias - AGI (Sevilla-España):

Sección Papeles de Cuba.

Sección Santo Domingo. Colección Mapas y Planos.

Sección Ultramar.

Archivo General de Simancas - AGS (Simancas-España):

Sección Secretaría General de Rentas.

Sección Secretaría y Superintendencia de Hacienda.

Archivo Museo Histórico de la Ciudad - AHMC (C. de La Habana).

Fondo: Actas Capitulares de La Habana. Libros correspondientes a los Siglos XVII y XVIII.

Archivo Nacional de Cuba - ANC (La Habana-Cuba):

Fondo: Protocolos Notariales de La Habana.

Fondo: Anotadurías de Hipoteca.

Fondo: Escribanía de Varios.

Fondo: Bienes del Estado.

Fondo: Junta de Fomento.

Biblioteca Nacional de Cuba, «José Martí»:

Fondo de Pérez Beato. Cartas. Documento Número 968.

\section{REFERENCIAS BIBLIOGRÁFICAS}

Arango y Parreño, Francisco, Obras Completas de Don Francisco de Arango y Parreño, 2 Tomos, La Habana, Publicaciones de la Dirección de Cultura, del Ministerio de Educación, 1952.

Cornide, María Teresa, La Habana de siglos y de familias, La Habana, Ciencias Sociales, 2005.

Deer, Noel, The history of sugar, 2 Ts., Londres. Ed. Chapman and Hall Ltd, 1942. 
Egórova, Olga, Agustín de Betancourt. Secretos cubanos de un ingeniero hispanoruso. La Habana, Casa editora Abril, 2010.

Funes Monzote, Reinaldo, De los bosques a los cañaverales. Una historia ambiental de Cuba 1492 a 1928, La Habana, Ciencias Sociales, 2008.

García Diego, J. A., En busca de Betancourt y Lanz, Madrid, Editorial Castalia, 1985.

García Rodríguez, Mercedes, Misticismo y capitales. La compañía de Jesús en la economía habanera del siglo XVII, La Habana, Ciencias Sociales, 2000.

García Rodríguez, Mercedes, La Aventura de fundar ingenios. La refacción azucarera en La Habana del siglo XVIII, La Habana, Ciencias Sociales, 2004.

García Rodríguez, Mercedes, Los ingleses en el tráfico e introducción de esclavos en Cuba. 1715-1739, La Habana, Editorial Historia, 2006.

García Rodríguez, Mercedes, Entre Haciendas y Plantaciones. Orígenes de la manufactura azucarera en La Habana, La Habana, Ciencias Sociales, 2007.

González-Ripoll Navarro, María Dolores, Cuba, la isla de los ensayos. Cultura y sociedad (1790-1815), Madrid, CSIC, 1999.

Moreno Fraginals, Manuel, El Ingenio, Complejo económico social cubano del azúcar, 3 Tomos, La Habana, Editorial Ciencias Sociales, 1978.

Moreno Fraginals, Manuel, «La introducción de la caña de azúcar y las técnicas árabes de producción azucarera en América», García Arenal, Mercedes (compiladora), Al-Andalus allende el atlántico, Granada, Universidad de Granada, 1997: 206-221.

Fecha de recepción: 3 de marzo de 2011

Fecha de aceptación: 15 de septiembre de 2011 


\section{Sugar and Modernity. The technological experimentation of the Havana oligarchy: 1700-1820}

The article discusses the mentality of modernization and technological experimentation which accompanied the enlightened elite of the Cuban sugar-producing oligarchy in the Eighteenth and Nineteenth Centuries. Data and documents show this powerful Havana group's noted interest in increasing the production of the sweet produce, what drove them to engage with English factories to produce modern-designed milis and construction materials that made them more durable and powerful. We'll show the diligence and persistence of the sugar-producing elite to achieve its economic and political goals and how through their spokesman Francisco de Arango y Parreño they demanded the King's permission for a technologicalindustrial espionage trip through Europe and the Caribbean that helped them to introduce new machines and modern technology. The investment capital accumulated by some members of the elite and the negotiations of the management of the Royal Trading Company of Havana in Cádiz, Bristol and London were fundamental to this process.

KeY WORDS: Sugar; sugar-producing technology; economy; engineers; Havana oligarchy; technological modernization; Eighteenth Nineteenth Centuries. 